\title{
Matchmaking through avatars: Social aspects of online dating ${ }^{1}$
}

\author{
Violetta Krawczyk-Wasilewska, \\ Department of Ethnology and Folklore, University of Łódź, Poland \\ Andrew Ross, formerly Oxford University
}

The new world of digital devices and social media is extending our notions of personal identity. The effects reverberate through many areas of modern social life, through the labour market, education, trade, and global news, all the way to social, family, and personal life. Powerful online applications and attractive social media running on the new devices are encouraging people to move into a new space, known as virtual space or cyberspace. In that new space, a person can deliberately remould or recreate his or her identity as a screen presence expressing an online personality, which is often pseudonymous following a widespread custom of using a new and invented name. In Internet jargon, the pseudonym is a nickname or a handle and is accompanied by a freely chosen graphic image to represent the person. People who live in different virtual communities often develop a plural identity arising from the sum of the various repertoires of their online roles.

Post-modern humans often use the new media to overcome the boundaries or limits of their physical embodiment and their given social position, as well as the constraints of their "tribal" or inherited traditions. Here is important to recall that for many centuries a conservative notion of identity was connected with the group identity, whereby a person who tried to live as an outsider faced a cruel vita nuda and social exclusion (Agamben 2010). Today people can transform some of the attributes of social stigmatisation into positive manifestations of their private "self" and individual identity. With the increasing salience of online life, the notion of privacy is slowly disappearing, and multiplying identities of a Protean type (Lifton 1993) are growing up. In real or physical life, the post-modern homo irretitus spends many hours a day in front of a computer screen. This lonely life is eased by communication with similar online addicts on social networking sites, by digital forms of entertainment such as television, music, and movies, and by addictive computer games. Such individuals will occasionally change their name and identity in order to feel free and anonymous. The changed identity is often accompanied by a graphical image. In the world of online social media and games, the image takes the form of a freely chosen and stylised graphic called an avatar.

\footnotetext{
${ }^{1}$ Paper delivered on the panel "Shaping virtual lives: identities on the Internet", during the 10th Congress of the Société International d'Ethnologie et de Folklore (SIEF), Lisbon, 18 April 2011.
} 
In Hindu tradition, the old Sanskrit term avatāra (meaning "descent") denoted the incarnation of a deity. Now the notion of an avatar has been updated to become a prominent part of post-modern culture. Since the first appearance online in 1985 of the beta version of a role-playing game invented by Chip Morningstar and Randy Farmer called Habitat (Morningstar \& Farmer 1986), the term avatar has come to denote the screen representation of an online gamer. In this new incarnation of the term, the gamer uses the mouse and keyboard, or a joystick, to control the movements of an animated screen figure that represents the gamer. The animated screen figure is the avatar.

Since that time, thanks to science-fiction authors such as William Gibson and Neal Stephenson (Gibson 1986, Stephenson 1992), as well as multitudes of online gamers (e.g., players of massively multiplayer online role-playing games, a.k.a. MMORPGs), the career of the new incarnation of the term has taken off. Now millions of online producers and consumers of video clips, mobile applications, social forums, and instant messaging services have avatars and have learned to recognise and appreciate the avatars their online peers deploy.

Global stardom for the new concept came in 2009 with the eponymous hero (also known as Jake Sully) of James Cameron's blockbuster movie Avatar (Cameron 2009, Ross 2010a). The virtual tribe of avatars was fruitful and multiplied in cyberspace, both in the form of the computer-generated three-dimensional action figures used to represent gamers in computer games and as the expressive two-dimensional icons (portrait photos and cartoon icons) that participants use to represent themselves on web forums and in other online communities. As avatars grew more prominent and pervasive on the Internet, it was inevitable that people would begin to use them for online dating.

Independently of the avatar story, online dating services first appeared in 1995, when the American corporation Match.com opened for business. Now the online dating industry has grown to include well over a thousand lifestyle and dating sites together with innumerable niche sites pairing people by race, sexual orientation, and religion, or offering online social contacts within specific circles (so finely sliced and diced as to cater just for women behind bars, or smokers and marijuana users, or Star Trek fans, to cite a few freely chosen examples). In the USA and UK, the online dating industry is the highest grossing online industry after video games and digital music. The eighth Internet Dating Conference, in Miami in January 2011, brought together business executives from over 500 companies involved in online dating.

Most online dating sites encourage their members to upload photos of themselves together with their profiles and browse the photos of other members (Krawczyk-Wasilewska 2006). The members then exchange mail and other online data to their hearts' content, or until they feel moved to go to the next level and meet in the flesh. On the biggest dating sites (e.g., eHarmony, Match.com), the machines do the matchmaking one-to-one, in social isolation (Epstein 2007). By contrast, on social networking sites such as Facebook (now with over 500 million 
members and still growing) or the company formerly known as MySpace (which once had over 100 million members) a community approach limits the intimacy of personal exchanges and enforces a keep-it-clean policy for any postings that other members of the online community can access. For this reason, much of the social interaction is not dating but rather public flirting: "although the social networking sites appeal mainly to young users and are not strictly dating sites, they bring the community back into whatever dating is generated there" (Epstein 2007, p. 35). When your friends can read your posts, you're not likely to start getting as intimate as you are when you think you're alone with your date. But in either case, social or one-on-one, the interactions are mostly via text.

In parallel to this development, software developers in the world of computer games created ever more addictive games based on 3D avatars, such as Second Life, invented in 2003 by Linden Lab, a financial giant hosting more than 20 million users (called residents) and IMVU (Instant Messaging Virtual Universe) founded by Will Harvey in 2004 (Harvey 2004). IMVU is a 3D graphical instant messaging client reportedly generated about $\$ 40$ million in revenue for the year 2010, and claimed over 40 million registered users and 6 million unique visitors per month (Wauters 2010).

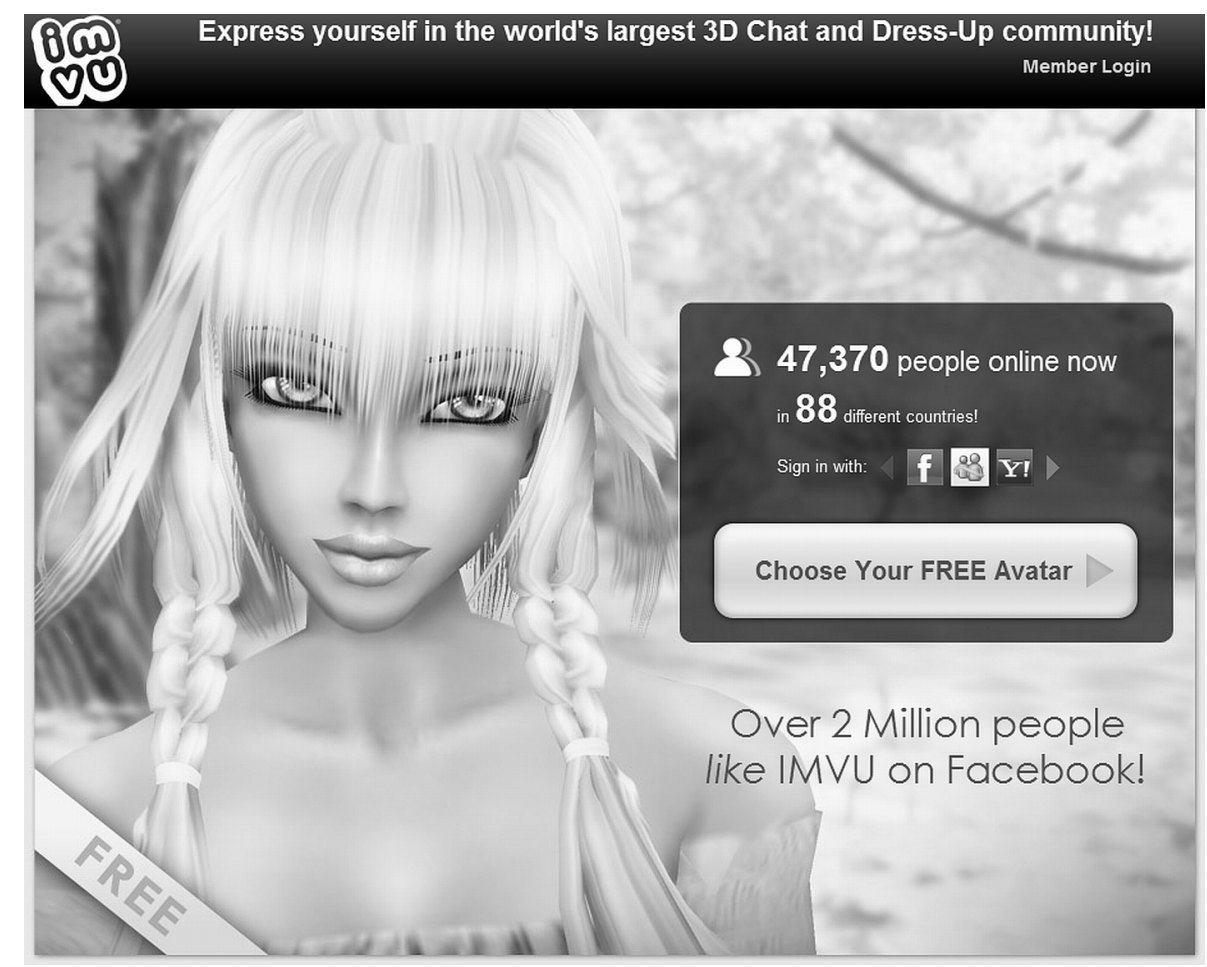

$I M V U$ 
In recent years, these technically more sophisticated games have popularised avatar dating within their virtual world, where the screen avatars do all the things virtually together that their owners might like to do with each other in the real physical world. Thus online dating developed to the next level (Frost et al. 2008).

Virtual dating combines online dating with online gaming. Virtual dating involves people using their avatars to interact in a virtual space that resembles a real-life dating environment, complete with photo-realistic 3D avatars and scenic props, where they can listen to music and play various games that provoke online conversation between the people behind the avatars. For example, in Second Life individuals can meet, chat, and flirt in a romantic virtual café in a city, such as New York, Paris, Cracow, or a tropical island resort.

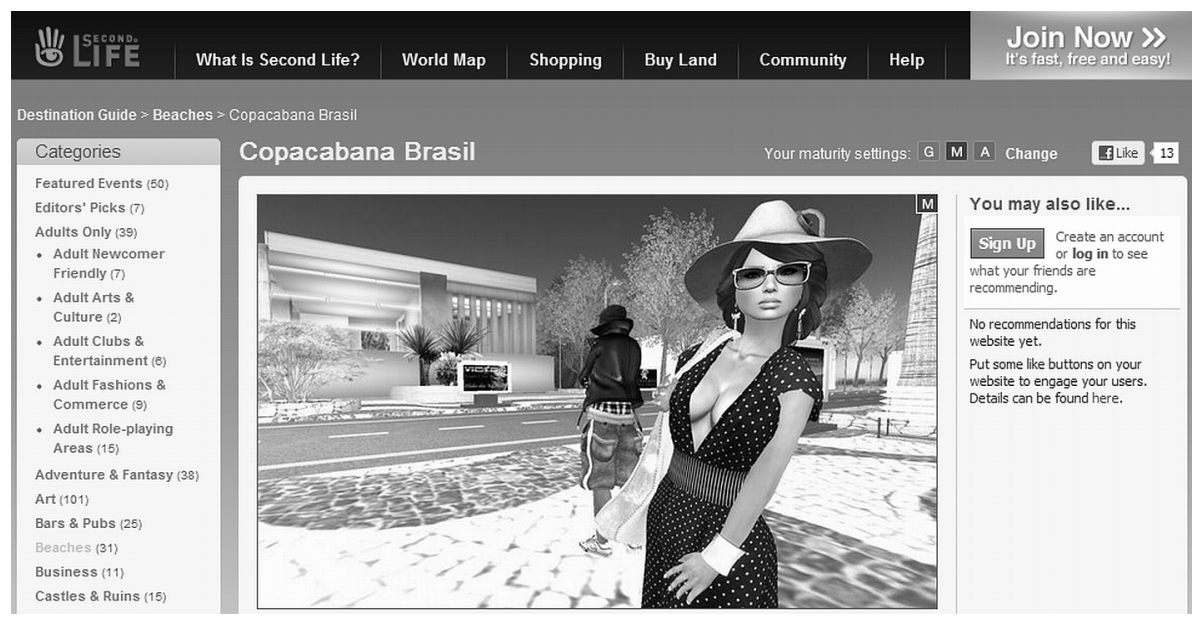

Exotic locations: a beach in Second Life

They can eat and drink in a virtual restaurant with their animated date, even though in reality the users are relaxing at home in their pyjamas, with no more than their mouse and keyboard to keep them busy and no risk of ruining their best outfits or succumbing to the temptations of too many gourmet calories. The animated screen dolls do all the usual human work of building up a relationship. They react to each other's every move, they gesture and speak at the whim of their owners, and when the date is done they even kiss goodbye, if the proceedings went as well as the pair of dreamers behind the avatars had hoped.

The avatars perform these ritualized mating games amid meticulously optimised atmospherics, where the streets and sidewalks are always clean and free of undesirable drunks or vagrants, the females are absurdly beautiful and unnaturally receptive, the males are impossibly handsome and clean-shaven, and any date can end in torrid sex where the partners keep going to unreal extremes. A user can often equip his or her avatar with an extensive array of pornographic accessories, and if the user is still bored or feels that the body image or persona or outfit is 
insufficiently alluring there is always the option to revamp everything with an instant virtual shopping expedition, for example, for a bigger bosom or a bolder dress or more muscular shoulders or a smarter suit. If you have an appetite for the best caviar and want to send a hundred roses to your avatar date, you can indulge your whim with artificial money, which is always available at a very reasonable exchange rate, all calculated, naturally, to maximise the revenue the online dating agency can generate from the user's real money. Naturally, too, the customers driving the avatars in their romantic escapades find their own hedonistic impulses escalating in their avatar world where the usual physical limits are replaced by virtual infinities, and human greed for unlimited consumer goods can drive the customers to become more and more addicted. All the while, the dating site's proprietors and their associates in all the subsidiary businesses that grow like mushrooms around these sites smile with joy as they watch the revenues accumulate in their bank accounts.

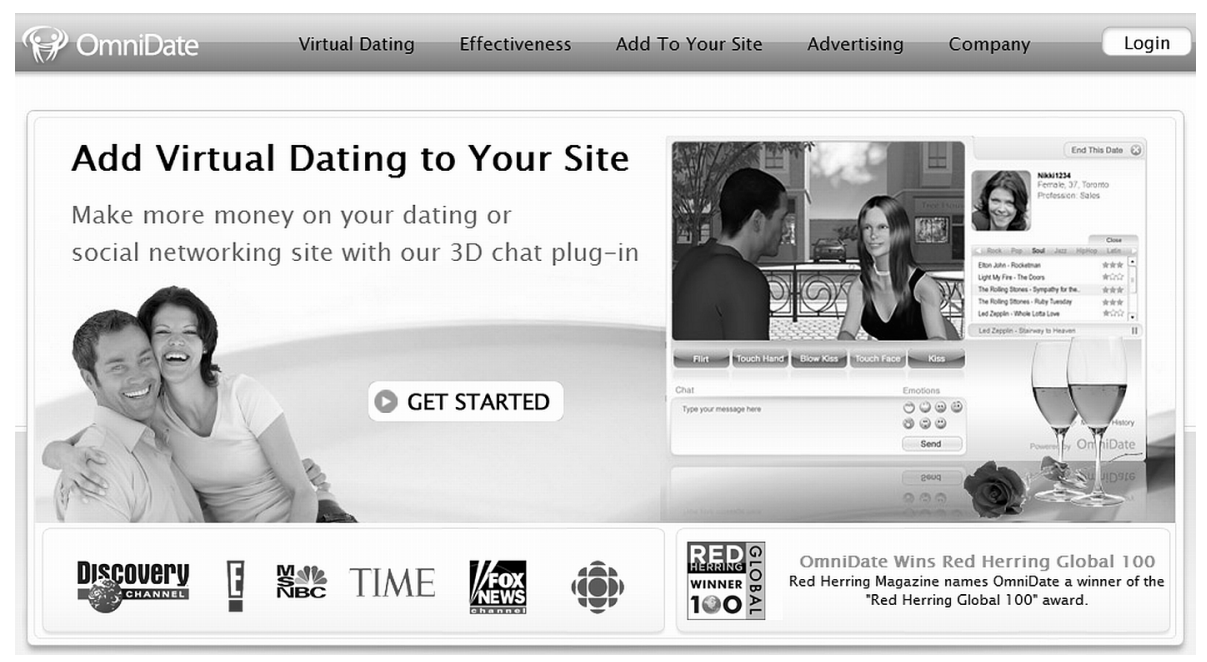

OmniDate, virtual dating for entrepreneurs

While even the technically less adventurous online dating sites allow members to select their partners on the basis of attributes such as education, income, and exact geographical location, avatar dating allows users to explore each other much more intimately for such attributes as compatibility of character, sense of humour, liking for fun, and emotional rapport, all of which enables the members to develop substantial friendships and satisfying relationships with people from anywhere in the world, people whose real names and faces they need never encounter. Moreover, most 3D social games offer special premium membership, allowing those prepared to pay for the privilege to enjoy all sorts of sexual acts between their avatars. This freedom stands in evident contrast to that on offer in the usual social networking applications, such as Facebook, where a family-friendly moral 
code prevails and nothing pornographic is allowed on the sites. But even the premium freedom is only a start. Any member can decide one day to make the transition from virtual interactions to the less exotic pleasures of more realistic dating online, with sharing of real names and photos of real faces and bodies, or even to go the whole hog and start dating offline.

Once a dedicated seeker after online romance has experienced the virtual delights of avatar dating in an online venue, taking that last step and going for a real, physical, face-to-face meeting with the person behind the avatar date can be a let-down. On the screen, the date was always radiant with surreal beauty, in a fashion-model world where women have wide eyes and curvaceous bodies, full lips and flawless complexions, and men are tall and well muscled, with full heads of hair, smooth chins and impeccable tans. Before that all-important first date in the physical world of everyday life, the seeker wore Seven Mile Boots and met his or her date in a virtual paradise. The avatars met in luridly coloured landscapes featuring flower-framed waterfalls and endless beaches sloping into turquoise seas, where after a drip-dry splash in the waves the pixel-perfect pair drive in a luxury limousine to a colourful restaurant serving dishes that look perfect but taste of nothing at all.

However the seeker personalised his or her online experiences, the virtual dates were mere chapters in a fairy tale jazzed up with pop-culture clichés. Moreover, on most dating sites the fairy tale was far from free of charge: users have to pay by the hour, the week, or the month, for their virtual dates and for all the virtual enhancements to the avatars and their circumstances that made those dates so special in memory. Whether the more fastidious users liked it or not, they paid for the kitsch artistry the web designers used to trick up their animated world, for the aesthetics of avatar dating are that of Barbie and Ken and similar products, styled to appeal to the broadest possible demographic and secure the profit margins. Perhaps this only reflects modern offline life, where local colour becomes ever more diluted in the globalised styling of goods designed in California and made in China.

Online dates are limited in other ways too: to keep the software programming task within bounds, the avatar exchanges that make up screen conversations with dates are probably selected from a predefined set of distinctly limited questions and answers, where users clicked on the least boring conversational gambit to take their avatar date another step forward and hopefully began to build up a meaningful picture of the likes and dislikes of the person behind their screen date's mask. At least one advantage of all this pointing and clicking will appeal to the fussy dater: if you don't like your date you can end the encounter instantly, painlessly, and move on to another avatar with another driver. Those unpleasant feelings you call forth in your date by rejecting them so summarily are safely hidden behind a remote screen. 


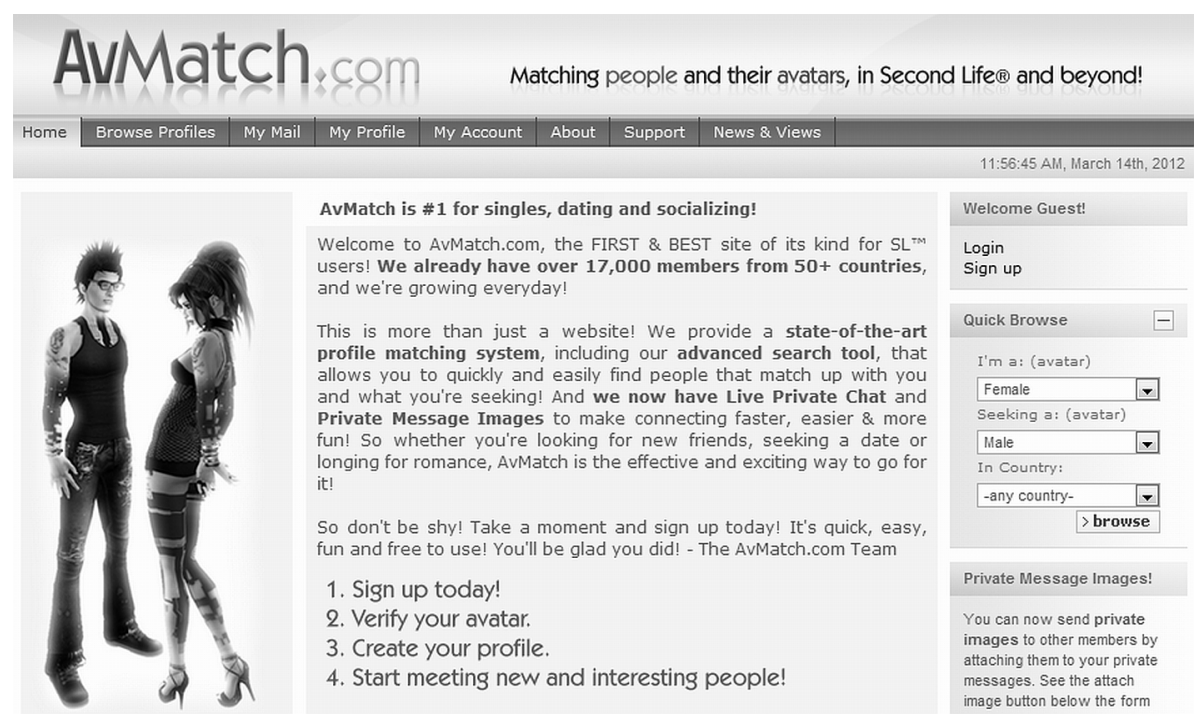

AvMatch, for avatar dating in Second Life

All this potentially addictive interactivity in virtual dating space has been possible since 2008, thanks to the pioneering efforts of Dave Wilkie and Stefan Embleton on their virtual dating site Weopia (which is based in Canada) (Wilkie \& Embleton 2008). The innovation was quickly replicated by OmniDate, AvMatch, RED Virtual Date, and others. Unlike the innovators behind Second Life, these new pioneers foresee that their avatar dating system will be used by real people who want to set up real-life dates with their screen companions in the fullness of time. The sites offer their services simply as a way of going on a virtual first date and recommend it as less time consuming, less expensive, and less hazardous than meeting at a local venue where anything and everything can go wrong.

Enthusiasts for the technology of virtual dating emphasize the sophisticated software behind the scenes. The programs offer unprecedented opportunities to establish deeper yet safer understanding with your online partner through mutual exploration in fantasy worlds, shared fun playing games you both know and enjoy, and digitally enhanced insight into your date's character and likeability. They are the best way known to their programmers of preventing disappointment on your first date in the real world. Reasonably enough, the advocates point out that virtual dating is much more friendly to women than, say, online dating based on web cameras or telepresence technologies that break through the wall of fantasy and pose a real danger of stalking and similar real-world problems.

Virtual dating apparently has the most appeal for teenagers, though older customers (in their 20s or 30s) are numerous enough too on the more popular sites. But much older users seem to be very rare; they seem to prefer the more oldfashioned and serious online dating sites where prospective partners are encouraged to post real photos of themselves accompanied by detailed and fact-laden 
profiles. For people beyond the first flush of youth, online dating is evidently a serious business, where the ticking of the biological clock takes all the fun out of fooling around in cloud cuckoo land. This merely reflects the facts in real life, where biologists and psychologists agree that there is no mystery as to why the most active daters, sexually, emotionally, and socially, are young people looking forward to a full life together with their new partners that will flower into children and all the rest. As to the fantasy side of avatar life, where multiple identities are almost the norm and nothing is quite as it seems, young people in real life too are often searching for their own identity and eager to try any new trick to help understand themselves a little better, even at the risk of a few bumps and bruises along the way.

People on virtual dates often project whimsical or distorted forms of themselves into the digital outlines of their avatars. These forms might somehow symbolise a real aspect of the personality of the user behind the mask, or they might just be a witty upside-down creature, but generally we can expect them to be a projection of a desired image (to be sexier, thinner, bolder, or stronger) inspired by pop culture stereotypes and ideals set by the latest celebrities. Complementing that choice, we can also expect that the other avatars people engage with or date in their romantic games reflect what the players tend to find attractive in the opposite sex (at least for heterosexual games - other players might prefer to play gay games in the safety of their online bubble worlds). The personal preferences we can expect to observe on both sides will reflect the ambitions of the players to be admired or desired, not only physically but also socially and mentally. The basic drive behind any virtually enhanced dating behaviour is wishful thinking - to be more intelligent, more witty, more experienced, more appealing, more blessed with social graces, and more attractive in general. Naturally, this drive animates not only online dating but also dating in the flesh, the traditional way, where the participants always plan the early steps obsessively to optimise the first impressions they make. The difference is that in the virtual case the brakes are off. It seems almost churlish to spurn the opportunity to incarnate oneself as a more amazing and more fabulous creature than one ever could in traditional online dating. In that world, even photos that have been painstakingly enhanced in Photoshop and résumés and profiles that have been edited and optimized to the point of untruth can do little to hide the facts of biology and economics. Given the point of traditional online dating, which is to smooth the transition to a physical date with a face-to-face meeting, there is little point in overdoing the creative input. By contrast, in all-out 3D avatar dating the residual link to everyday reality is so tenuous as to be negligible. Why not have fun and pretend to be Angelina Jolie and Brad Pitt for a day? The avatars are playdolls, and the wilder and wittier the play the better, so long as the players remember that their multiple identities are free creations of the human spirit, constrained only by the frames and the aesthetics offered by the site designer. Seen in this light, avatar dating is decoupled from its origins in human mate selection and becomes a sport or pastime in its own right, like tennis or Sudoku, with the 
fantasy limited less by the romantic or sexual appetites of the players than by their deeper psychology.

Several sociological and psychological studies have dealt with multiple virtual identities (Flew 2008; Riva \& Galimberti 2003; Turkle 1995, 2005). All of them start out from the idea that when people merge their human identity with the array of virtual prostheses that the avatars provide for them, they become virtual cyborgs. As such, they create transcendent selves that rise above their human biology and accept the fusion of human and machine that their online activities presuppose. As people transcend their biology to animate virtual agents in their virtual worlds, they find their relatively simple real identities fragmenting into a multiplicity of partial virtual identities, united by a transcendent self that no longer feels bound by the boring old biological facts of real life. The novelty of the cyborg self is its ability to change its character to suit its virtual circumstances. This brings advantages to the human behind the cyborg, such as the option to avoid face-to-face conversations for people who formerly feared their repercussions or the ridicule they once endured; the ability to express their views and opinions without discrimination or penalisation in the case of marginalised or persecuted groups; or the opportunity to encounter or to stimulate similar ideas among like-minded people. But these advantages are also accompanied by actual or possible disadvantages, such as the fact that many people, once given such virtual freedom, soon become addicted to their virtual lives and lose touch with their roots in physical reality, or the fact that as their online fluency increases they begin to lose their fluency in offline communication, especially in the sphere of social contacts (Carr 2010, Maushart 2011, Turkle 2011).

These psychosocial consequences of cultivating a more and more pervasive online life are brought to fever pitch in virtual dating, where deep human passions are entrained to the exchange of bits and bytes, because their virtual identity becomes of existential importance to the people who rely upon it to find sexual or romantic fulfilment. Those who in human life are timid or lack confidence have the chance at last to recreate themselves as they really want to be in the hope that through their online flirting and chatting they will succeed at least in experiencing the joys of cybersex and perhaps even in starting an offline relationship in the physical world. In all these endeavours, avatars give their owners the freedom to create their ideal incarnation - or at least give them a handy self, free from the perhaps cloying or oppressive restrictions of the real cultural norms and customs of the world they live in, and offer them a new way to feel and play with all the possibilities they may previously have yearned to explore. It is all too easy to idealise a potential partner in a virtual world, but it also gratifyingly easy to idealise one's own self there and enjoy a new freedom.

Given all these consequences, both actual and possible, it is only right to point out that many people who thus live out their fantasy lives online start off by finding the whole experience a matter of fun and games but slowly find themselves resenting the reality they left behind. They may even go on to inflict pain, 
depression, and suffering not only upon themselves but also upon their parents, families, spouses, partners, and friends. The online players who become most addicted need psychological help. On the other hand, avatars and virtual realities are quickly becoming invaluable tools in the toolkit of modern psychiatry as effective means to cure phobias and as useful weapons in cognitive therapy for anxiety disorders (Gaggioli et al. 2003), in both cases because the avatar is an active and steerable representation of the patient embedded in a realistic world. Avatars technology has become an integral part of digital communication for general users thanks to its anonymity, safety, comfort, and easy access (Whitty \& Carr 2006, p. 50). A range of problems arise from the opportunities the technology creates for deception through the use of false identities, for harassment of a victim with unwanted communications, and indeed for infidelity among the devotees of avatar dating, but all these problems existed in one form or another in pre-digital life too.

Before we go on to consider the future of avatar dating and matchmaking, it is worth pausing to emphasize the paradox behind online dating. The popularity of the practice is grounded in a strange fact about human nature: all of a person's intimate relationships in real life need to be reinforced by close and constant physical contacts in order to survive, which gives the potentially runaway world of the inner passions a strong and effective anchor in everyday being; whereas in cyberspace the hindrance imposed by physical distance is essentially overcome, and at the same time the psychic engagement is made more intense, which causes a positive feedback that reinforces the emotional attachments (Ben-Ze'ev 2004, p. 53). Without the massive inertia of his or her physical being, a person's inner feelings can run riot, causing such an obsession with the online target that things can go badly wrong. On the other hand, the same freedom from inertia can allow mutual epiphanies of the spirit that make life worth living again for those who once despaired. The paradox is not new to digital media: generations ago it was summed up in the folk wisdom that absence makes the heart grow fonder.

Avatar dating has a lot going for it. In physical relationships, people often hide their true feelings and inner fantasies, their 'bad' inclinations and 'naughty' dreams, and the harder knocks that the university of life has dealt them, but all these blocks are lifted when they can express themselves through their avatars. Problematic personal features like shyness, social phobias, poverty, physical unattractiveness, traumatic experiences, disability, and other social barriers can all disappear while two people date each other with avatars. These benefits are evidently compelling enough to persuade more and more people to try it.

Altogether, the future of avatar dating looks good. People who explore each other through avatars have at their disposal a tool of unprecedented power to cut through the psychosocial barriers that can make dating in the physical world such a bore. As the technology matures and the avatars become more realistic, until we can all live as wholeheartedly in our virtual worlds as Jake Sully did in the movie Avatar, the attraction of avatar dating can only increase. Much as airline pilots 
today spend most of their training hours 'flying' in simulators, so future married couples might spend more time getting to know each other on avatar dates than in the flesh. In any case, the technology is here to stay (Ross 2010b, pp. 12-29).

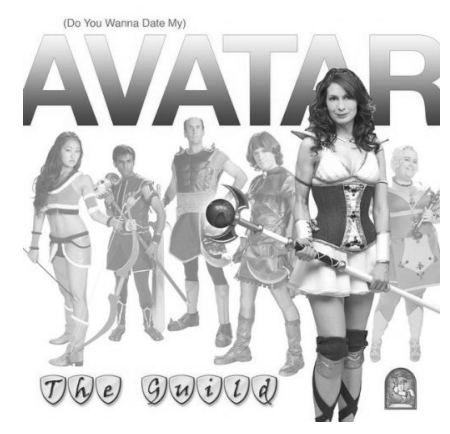

Hang with me in my MMO

So many places we can go

You'll never see my actual face

Our love, our love will be in virtual space

I'm craving to emote with you

So many animations I can do

Be anything you want me to be

$C$ 'mon, c'mon and share a potion with me

Do you wanna date my avatar?

She's a star

And she's hotter than reality by far

Wanna date my avatar?

"(Do You Wanna Date My) Avatar"

(Day \& Whedon 2009)

\section{References}

Agamben, G. (2005): Nudita. Rome: Nottetempo. Polish translation: Nagosc, Warszawa: W.A.B., 2010.

Ben-Ze'ev, A. (2004): Love Online. Emotions on the Internet. Cambridge:

Cambridge University Press.

Cameron, J. (director) (2009): Avatar. Twentieth-Century Fox.

Carr, N. (2010): The Shallows: What the Internet Is Doing to Our Brains. New York: W. W. Norton \& Co.

Day, F. \& J. Whedon (2009): Do you wanna date my avatar? The Guild song, lyrics at: http://www.lyricsreg.com/lyrics/the+guild/do+you+wanna+date+my+avatar/ (accessed 6 March 2012).

Epstein, R. (January 30, 2007): The truth about online dating. Scientific American, pp. 28-35. http://www.scientificamerican.com (accessed 6 March 2012)

Flew, T. (2008): New Media: An Introduction. 3rd edition. Melbourne:

Oxford University Press. 
Frost, J., et al. (2008): People are experience goods: improving online dating with virtual dates. Journal of Interactive Marketing, Vol. 22, No. 1, pp. 51-61.

Gaggioli, A., et al. (2003): Avatars in clinical psychology: a framework for the clinical use of virtual humans. Cyberpsychology and Behavior, Vol. 6, No. 2, pp. 117-125.

Gibson, W. (1986): Count Zero. London: Victor Gollancz.

Harvey, W. (2004): Instant Messaging Virtual Universe (IMVU). http://www.virtualworldnews.com/2009/04/imv/ (last accessed 1 April 2011).

Krawczyk-Wasilewska, V. (2006): E-folklore in the age of globalization. Fabula: Journal of Folktale Studies, Vol. 47, Nos. 3-4, pp. 248-254.

Lifton , R.J. (1993): The Protean Self: Human Resilience in the Age of Fragmentation. New York: Basic Books.

Maushart, S. (2011): The Winter of Our Disconnect. London: Profile Books.

Morningstar, C. \& R. Farmer (1986): Habitat. Lucasfilm Games.

Riva, G. \& C. Galimberti (eds.) (2003): Towards Cyber Psychology: Mind, Cognition and Society in the Internet Age. Amsterdam: IOS Press.

Ross, A. (2010a): Avatars 'r' us. Movie review, 2 pages. http://www.andyross.net (accessed 6 March 2012).

Ross, A. (2010b): G.O.D. Is Great: How to Build a Global Organism. Germany: Ross Verlag.

Stephenson, N. (1992): Snow Crash. New York, Bantam Books.

Turkle, S. (1995): Life on the Screen: Identity in the Age of Internet. New York, Simon \& Schuster.

Turkle, S. (2005): The Second Self: Computer and the Human Spirit. Cambridge, MA: MIT Press.

Turkle, S. (2011): Alone Together: Why We Expect More from Technology and Less from Each Other. New York: Basic Books.

Wauters, Robin (2010): IMVU hits $\$ 40$ million annual revenue run rate. TechCrunch: http://techcrunch.com/2010/04/24/imvu-revenue/ .

Whitty, M. \& A. Carr (2006): Romance Psychology of Online Relationships. Basingstoke: Palgrave Macmillan.

Wilkie, D. \& S. Embleton (2008): Weopia. http://www.weopia.com (offline and being upgraded at time of writing).

URLs for illustrations (all accessed 14 March 2012):

http://www.imvu.com/

$\mathrm{http}: / /$ secondlife.com/destination/copacabana-brasil

http://www.omnidate.com/

http://www.avmatch.com/

http://en.wikipedia.org/wiki/File:Wanna_date_my_avatar.jpg 